\title{
The Emperors of scientific versatility that influenced Clinical Medicine; Dr Golding Bird and Nikola Tesla
}

\author{
Gayathri Delanerolle ${ }^{1}$, Rawan Ebrahim ${ }^{2}$, Will Goodinson ${ }^{3}$, Kathryn Elliot ${ }^{4}$, Ashish \\ Shetty $^{5}$, and Peter Phiri ${ }^{4}$ \\ ${ }^{1}$ University of Oxford \\ ${ }^{2}$ University College London \\ ${ }^{3}$ University College London Hospitals NHS Foundation Trust \\ ${ }^{4}$ Southern Health NHS Foundation Trust \\ ${ }^{5}$ University College London Faculty of Medical Sciences
}

March 23, 2021

\begin{abstract}
Physics and Chemistry are fundamental composites of medicine. Concepts and theories from these fields continuously influence modern day medicine, including the development of novel diagnostic methods, pharmacological and surgical interventions and inadvertently, patient care. The use of scientific approaches to improve existing clinical practices is important to understand. This includes the exploration of key innovators that were ahead of their time when inventions were developed to support "the collateral sciences". Two such innovators are Golding Bird and Nikola Tesla; 2 unique and incredibly versatile scientists. Electrotherapeutics has had a remarkable history. The use of Torpedo Fish (Torpedo mamorata, Malopterurus electricus) to provide analgesia was reported by Scribonius Largus in AD 47 in his monumental work Compositiones Medicae
\end{abstract}

\section{Perspective}

The Emperors of scientific versatility that influenced Clinical Medicine; Dr Golding Bird and Nikola Tesla

Authors

Gayathri Delanerolle $^{1}$, Rawan Ebrahim ${ }^{2}$, Will Goodinson ${ }^{3}$, Kathryn Elliot $^{5}$, Ashish Shetty ${ }^{2,3}$, Peter Phiri ${ }^{4,5}$ Affiliations

${ }^{1}$ University of Oxford, Oxford Brain Health Clinical Trials Unit, Department of Psychiatry, Warneford Hospital, Oxford OX3 7JX, UK

${ }^{2}$ University College London, UK

${ }^{3}$ University College London NHS Foundation Trust, UK

${ }^{4}$ University of Southampton, Primary Care and Population Sciences and Medical Education, Aldermoor Health Centre, Southampton, SO16 5ST, UK

${ }^{3}$ Southern Health NHS Foundation Trust, Research \& Development Department, Southampton, SO30 3JB, UK

Corresponding Author: 
Dr Peter Phiri, PhD

Southern Health NHS Foundation Trust

Research \& Development Dept.

Clinical Trials Facility, Moorgreen Hospital

Southampton, SO30 3JB, UK

Email:peter.phiri@southernhealth.nhs.uk

Word count: (1,908 words)

Keywords: Golding Bird, Nikola Tesla, AI, neuromodulation, electrotherapy, pain management

"From time to time in the rare intervals, the great spirit of discovery finds itself on earth to communicate the mystery that will advance mankind. It selects the most able, the most deserving and whispers it's secret into his ear. As a flash of light emerges valuable knowledge. While catching the hidden meaning the lucky one observes a magical change... Miracles that he sees, although distant in time, will come to materialise. He knows it, there is no shred of doubt in his mind, in every fibre of his body he feels - it is a Great idea. "Nikola Tesla

\section{Introduction}

Physics and Chemistry are fundamental composites of medicine. Concepts and theories from these fields continuously influence modern day medicine, including the development of novel diagnostic methods, pharmacological and surgical interventions and inadvertently, patient care. The use of scientific approaches to improve existing clinical practices is important to understand. This includes the exploration of key innovators that were ahead of their time when inventions were developed to support "the collateral sciences". Two such innovators are Golding Bird [Figure 1] and Nikola Tesla [Figure 2], two unique and incredibly versatile scientists.

Electrotherapeutics has had a remarkable history. The use of Torpedo Fish (Torpedo mamorata, Malopterurus electricus) to provide analgesia was reported by Scribonius Largus in AD 47 in his monumental work Compositiones Medicae.

Figure 1

\section{Golding Bird: Life and Contributions to Electrotherapeutics}

Dr Golding Bird was a medical pioneer who used electricity as a therapeutic principle. He was one of the earliest clinicians to use electricity for a selected population of patients advocating that it may have various other uses as well. Electrotherapeutics is increasingly being recognised as an important tool for the success of the treatment of pain in the last two decades.

Golding Bird was born in Norfolk, England on 9 December 1814 [1] and had an unremarkable upbringing although he suffered from rheumatic fever and endocarditis as a child, which affected his long-term health. He was privately educated with a focus on classical education instead of the sciences, although he grew an interest in both botany and chemistry and quickly displayed a great ability in these fields, volunteering to give lectures and tutorials to his classmates outside of official lessons [2].

Golding Bird was always interested in medical sciences. He became a student at Guy's Hospital in 1832. Guy's hospital was founded in 1721 by Thomas Guy and had a tradition of studying physics and chemical applications to medicine. Thomas Addison, Thomas Hodgkin, Sir Ashley Cooper, Sir Alexander Fleming, and John Braxton Hicks were among the Physicians who worked at Guys Hospital. By 1836, Bird was in charge of the department for the treatment of patients by electricity and galvanism at the medical school of Guy's under the supervision of Dr Thomas Addison. During this period, Guy's had become notable 
amongst the public for his use of electricity for the management of various pain and medical conditions. Dr Bird was likely chosen to be in charge of the department because of his prior experience with electrical therapy. In the 1830s, there were great strides being made in the area of electrotherapeutics, however it was still very limited in its use. The treasurer of Guy's Hospital, who felt that the hospital could treat more patients with electrotherapeutics, approved the development of an electrical room with a senior clinician supervising Golding Bird. Bird received lots of experience in electrotherapeutics as a medical student and was introduced to the use of many advanced pieces of equipment including the galvanic cell, the faradic coil, and static electricity moxa [2].

The 'electrifying room' at Guy's was then placed under the general direction of Dr Bird when he became the head of the department, where he used devices eliciting electrical treatments. The electrolytic effects produced long-continued currents at low tension interested Golding Bird, since they appeared to be analogous to the nervous currents in the body. Golding Bird discovered the 'electric moxa', to treat movement disorders and more notably treated pelvic pain and paralysed bladders through the application of a strong electric current between the sacrum and the pubis. Bird used both electrochemical and electrostatic machines [2] for electrotherapy. Treatment modalities included peripheral nerve stimulation and muscle stimulation.

Bird was ahead of this time and his work was perceived controversial and debated extensively, especially during dissemination knowledge by way of lectures [1]. These lectures [1] combined with the transformative knowledge basis to conceptualising the advancement of neuromodulation; Bird's work was revived in the modern era to exploit electrotherapy. Additionally, Bird is more known for being the inventor of the flexible stethoscope [3]. Golding Bird encouraged electrotherapy to be used only when all the traditional methods had failed. It has become clear now that patient selection is vital to the success of neuromodulation. Golding Bird died from a urinary tract infection on 27 October 1854 [4]. His frail health and overwork have been attributed to his death at an age of 39 .

\section{The Golding-Bird gold medal for sanitary science}

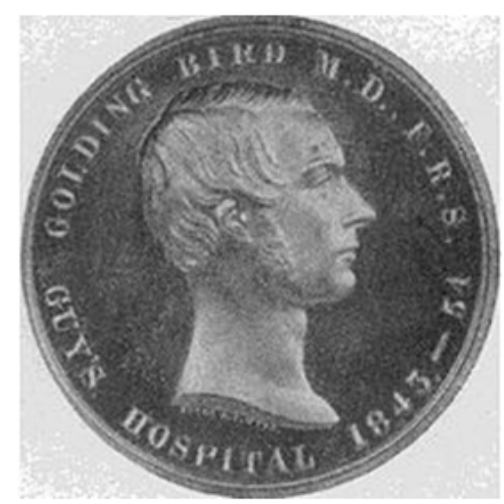

Figure 3

Soon after his passing, the Golding Bird Gold Medal and Scholarship for Sanitary Science, seen in figure 3, was established by his wife Mary and was awarded annually at Guy's teaching hospital from 1887 all the way until 1983. From 1934 onwards, a Golding Bird Gold Medal and Scholarship was also awarded for Obstetrics and Gynaecology. The neurostimulation practices have continued at Guy's Hospital after Bird's and the inauguration of the Department of Electricity on July 15th. There can be no doubt that Dr Bird's contributions to the field of neuromodulation were significant. He helped to pave the way for the development of the vast majority of clinical tools at the disposal of our physicians today.

\section{Nikola Tesla: Life and Contributions to Electrotherapeutics}


Similar to Bird, Nikola Tesla [Figure 2] was an innovator who was ahead of his time. However, he is celebrated in the modern world for his scientific contributions. Many in society reap the benefits of scientific advancements associated with Tesla, without knowing its aetiological origins. This would be an apt case, when considering Tesla, a man who many millennials know because of Elon Musk's efforts to create an eco-friendly industrial advancement. More so than ever, people have become more interested in Nikola Tesla as Musk decided to name his fleet of electric cars, "Tesla" to honour the use of Tesla's designs and concepts. This inspired generations of consumers and otherwise, to "Google" the meaning of "Tesla" which prompted discussions around one of the greatest scientists of the 20th century. Contrary to this notion, most clinicians know of Nikola Tesla for a variety of reasons as his patents resulted in the development of many different medical equipment and devices, especially in Clinical Radiology, Nuclear Medicine, Neurology, Oncology and Trauma Surgery. However, a relatively unknown fact is that Tesla's patents and scientific reasoning is invaluable to the advancements in clinical trials and methodological designs to test technologies and devices. To explore this further, it is important to understand Tesla and his work.

Nikola Tesla was born on the 10th of July 1856 in Smiljan, Croatia. Tesla is undoubtedly one of the most understated inventors of modern times despite having 300 patents to his name and has made one of the most important contributions to the field of high frequency and voltage electrical currents. In addition, Tesla was well known for his versatility as he focused on multiple areas of science. Whilst he was a great inventor, most of the academic community criticised him for completing 24 publications throughout his lifetime without realising, each had wider impact than any others seen at the time and this misconception, prevented Tesla from receiving any academic honours. This is further evident as Tesla's contributions are not well discussed in academia compared to Albert Einstein or Thomas Edison, despite the impact of his theories and applications across various genre. This is of course until the revival of his work by Elon Musk and the likes of Rohit Prasad, Steve Jobs and Steve Wozniak.

In 1891, Tesla showed that the rapid oscillation currents could cross the human body without the cause of any muscle spasms or tissue damage [5]. This was a sensational discovery as it showed the possibility of therapeutic application and provided the basis to modern day ultrasound. This methodology was further used by Tesla to create an oscillator to relieve fatigue from leg muscles that is used in the treatment of modern-day musculoskeletal conditions. Following on from these discoveries, the Tesla coil and wireless remote controls were developed which is widely used within medical equipment in the modern day. Tesla's theory and design of wireless streams is used in modern day technology that is applied to both diagnostic and therapeutic procedures such as HIFU. The same principles are also applicable in clinical trials used to test medical devices, technologies and equipment commonly seen in the 21st century. In 1896, Tesla also used high frequency currents to design an ozone generator to produce ozone with antiseptic and antibacterial properties. This concept was later used in bacteriology and vaccinology production as well as developing and designing aseptic pharmacy units required for clinical trials that comply with Good Manufacturer Production (GMP) standards.

The most useful discovery of all of course is Tesla's concepts in Artificial Intelligence (AI) that he demonstrated in 1898 at the Madison Square Garden Electrical Exhibition [6]. At the time, his exhibit was the world's first AI project, which was a radio-controlled vessel, seen in figure 4, and he described that the boat has a 'borrowed mind'. His design and methods for this were patented (613:809) and he made it a point to generalise the knowledge as much as possible. Thus, Tesla's device marks the birth of Robotics. Furthermore, an innovation within the circuitry of the boat was referred to, as "logic gate" became a vital steppingstone to semiconductors. This work resulted in the development of the first industrial robot in 1961 that led to the current theorems in medical technologies [6]. Similarly, these methods were used to develop robots for surgical procedures that was pursed by the Interventional Clinical Trials Unit at UCL/UCLH that provided multiple inventions to the NHS for across specialties of urology, gynaecology, bariatrics and general surgery in head and neck, colorectal and hepatobiliary. Furthermore, Tesla's "logic gate" and primary patent influenced the modern-day smart speakers like Amazon's echo to missile-firing drone aircrafts and the rise to an entire section of applied sciences; referred to as operational research. 


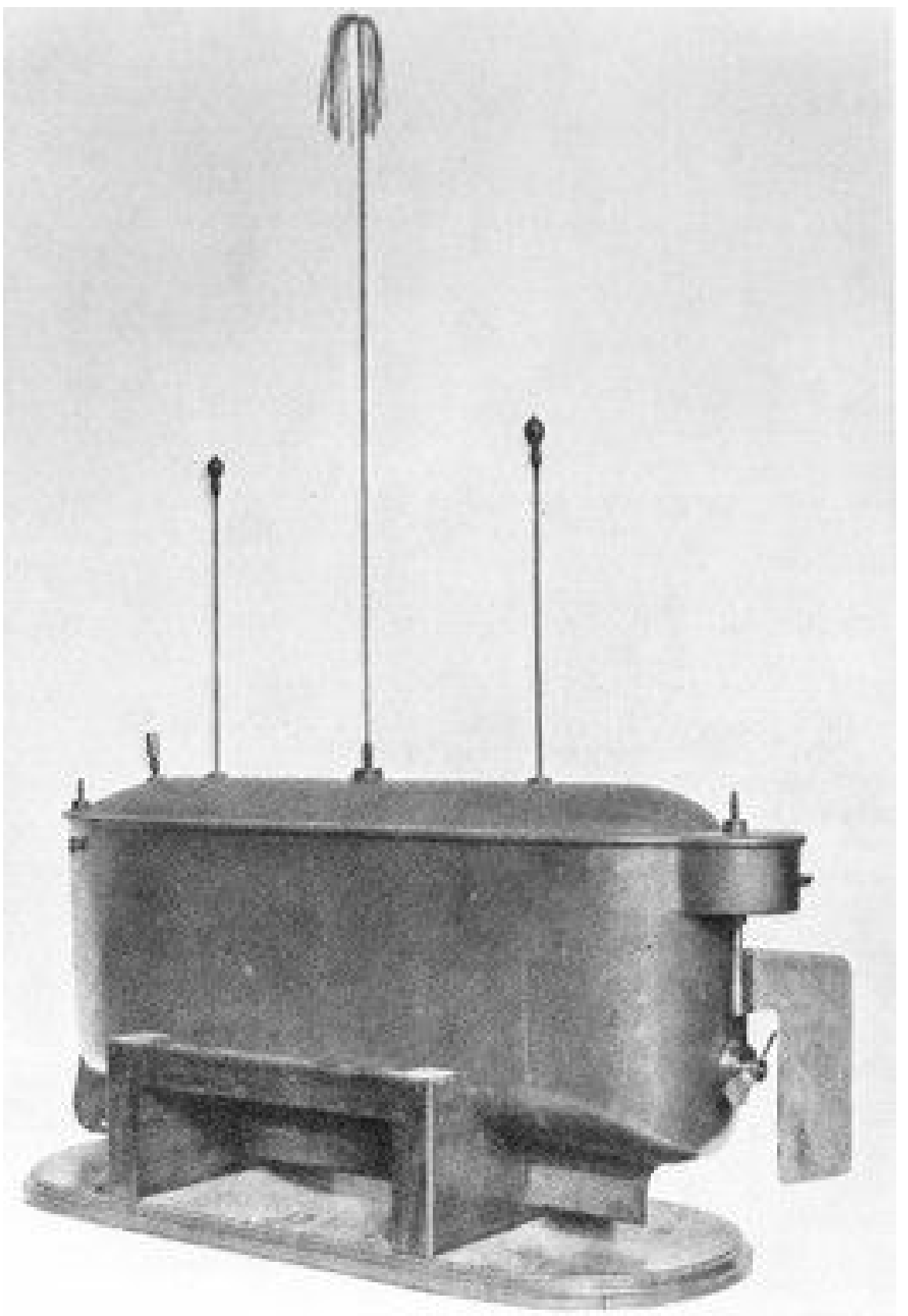

Figure 4

It is evident, Tesla's gift was to explore science in the most intellectual way possible and in many ways, and he was ahead of his time. His words often did not make sense to many listeners, as his mind was a complex web of ideas. He could visualise highly complex systems in his mind with extreme precision and would often say that he can build anything that is in his mind.

\section{Conclusion}

Perhaps the most impressive element of all is that the noble achievements of Dr Bird and Nikola Tesla 
pioneered a field of intrigue that the modern world has yet to fully understand. The words AI and medical technologies are ubiquitously thrown around but in comparison to other disciplines, it is still in its infancy. Whilst the sciences and medicine subsequently evolved, our ability to translate its' deepest conceptual and theoretical understanding has helped clinicians around the world take one step closer to the ultimate objective of personalised and evidence-based medicine leading to optimal clinical care.

Declarations

None

Funding - none

\section{References}

1. King's College London Archives "BIRD, Golding (1814-1854)" Ref: GB0100 G/PP1/4

2. The collateral sciences in the work of Golding Bird (1814- 1854); N.G.Coley

3. Wilks, Samuel; Bettany, G. T., "Dr. Golding Bird", A Biographical History of Guy's Hospital, London: Ward, Lock, Bowden \& Co. 1892

4. Steel, Robert, "Dr. Golding Bird, the physician", Doing Good, or, the Christian in Walks of Usefulness, pp. 206-214, Philadelphia: Perkinpine and Higgins, 1859

5. N. Tesla, "High Frequency Oscillators for Electro-Therapeutic and Other Purposes", in Proceedings of the American Electro-Therapeutic Association, American Electro-Therapeutic Association. p. 25.

6. SERBIAN JOURNAL OF ELCTRICAL ENGINEERING Vol. 3, No. 2, November 2006, 163-175

\section{Hosted file}

Figure 1.pdf available at https://authorea.com/users/403427/articles/514876-the-emperorsof-scientific-versatility-that-influenced-clinical-medicine-dr-golding-bird-and-nikolatesla

\section{Hosted file}

Figure 2.pdf available at https://authorea.com/users/403427/articles/514876-the-emperorsof-scientific-versatility-that-influenced-clinical-medicine-dr-golding-bird-and-nikolatesla

\section{Hosted file}

Figure 3.pdf available at https://authorea.com/users/403427/articles/514876-the-emperorsof-scientific-versatility-that-influenced-clinical-medicine-dr-golding-bird-and-nikolatesla

\section{Hosted file}

Figure 4.pdf available at https://authorea.com/users/403427/articles/514876-the-emperorsof-scientific-versatility-that-influenced-clinical-medicine-dr-golding-bird-and-nikolatesla 